\title{
PERIODIZAÇÃO CURRICULAR NA EDUCAÇÃO ESCOLAR
}

\author{
Antonio Leonan Alves Ferreira ${ }^{1}$
}

\begin{abstract}
RESUMO
Este texto delineia alguns apontamentos sobre a periodização curricular na educação escolar. Analisa a relação entre a produção do objeto curricular e o tratamento do tempo no processo de trabalho educativo a partir da pedagogia histórico-crítica. Como resultado, por um lado, elaborou-se um plano de generalização para orientar teórico-metodologicamente a investigação sobre a periodização curricular na educação escolar a partir da pedagogia históricocrítica; por outro, analisou-se a relação social que constitui a periodização curricular e configurou-se alguns de seus componentes no processo de trabalho educativo na educação escolar.
\end{abstract}

Palavras-chave: Periodização curricular. Pedagogia histórico-crítica. Psicologia histórico-cultural.

\section{CURRICULUM PERIODIZATION IN SCHOOL EDUCATION}

\begin{abstract}
This text outlines some notes on the curricular periodization in school education. It analyzes the relationship between the production of the curricular object and the treatment of time in the educational work process based on historical-critical pedagogy. As a result, on one side, a generalization plan was made to orient in a methodological-theoretical sense the investigation about curricular periodization on school teaching through critical-historical pedagogy; on another sid, the social relation that constitute the curricular periodization was analyzed and was based on some of the its components on the educational work process.
\end{abstract}

Keywords: Curricular periodization. Historical-critical pedagogy. Historical-critical psychology.

\section{PERIODIZACIÓN CURRICULAR EN EDUCACIÓN ESCOLAR}

\section{RESUMEN}

Este texto esboza algunas notas sobre la periodización curricular en la educación escolar. Analiza la relación entre la producción del objeto curricular y el tratamiento

\footnotetext{
1 Pós-doutor em Filosofia e História da Educação (UNICAMP); Instituto Federal de Educação ciência e Tecnologia Baiano - IF Baiano - Brasil; Professor do Mestrado Profissional em Educação Profissional e Tecnológica - IF Baiano; Grupo de estudos e pesquisa Laboratório Escola - CNPq/IF Baiano. Orcid iD: https://orcid.org/0000-0003-0270-4389. E-mail: leonanferreira@gmail.com
} 
del tiempo en el proceso de trabajo educativo a partir de la pedagogía históricocrítica. Como resultado, por un lado, se elaboró un plan de generalización para orientar teórico-metodológicamente la investigación sobre la periodización curricular en la educación escolar a partir de la pedagogía histórico-crítica; por otro lado, analizamos la relación social que constituye la periodización curricular y configuramos algunos de sus componentes en el proceso de trabajo educativo en la educación escolar.

Palabras clave: Periodización curricular. Pedagogía histórico-crítica. Psicología histórico-cultural.

\section{INTRODUÇÃO}

O presente texto delineia alguns apontamentos sobre a periodização curricular na educação escolar. Analisa o problema da produção do objeto curricular e o tratamento do tempo no processo de trabalho educativo, a partir da pedagogia histórico-crítica. Toma a relação social que produz os objetos da realidade em suas dimensões ontológicas, gnosiológicas e axiológicas (LOMBARDI, 2010), para analisar a relação social que constitui a periodização curricular, a fim de configurar alguns de seus componentes no processo de trabalho educativo na educação escolar.

Entendi que a constituição da natureza da periodização curricular é a relação entre o ser (conhecimento e desenvolvimento) e o trato do tempo, na particularidade do processo de trabalho educativo na educação escolar, em condições histórico-sociais objetivas. Assumindo como referência esta relação, realizei aproximações analíticas com campos disciplinares do processo de trabalho educativo na educação escolar, a fim de apreender e explicar algumas de suas determinações, e assim, contribuir para o diálogo científico sobre a periodização curricular a partir da pedagogia históricocrítica.

Assim, por um lado, elaborou-se um plano de generalização para orientar teórico-metodologicamente a investigação sobre a periodização curricular na educação escolar a partir da pedagogia histórico-crítica; por outro lado, analisou-se a relação social que constitui a periodização curricular e configurou-se alguns de seus componentes no processo de trabalho educativo na educação escolar em geral e na particularidade de 
uma disciplina escolar, destacando alguns fundamentos da periodização curricular neste tipo particular de atividade.

\section{A CONSTRUÇÃO DO OBJETO CURRICULAR E O TRATAMENTO DO TEMPO NO PROCESSO DE TRABALHO EDUCATIVO A PARTIR DA PEDAGOGIA HISTÓRICO- CRÍTICA}

Se para a teoria da ciência o problema fundamental do conhecimento é a relação entre o ser e a consciência², e para a teoria da ciência pedagógica o problema fundamental da pedagogia é a relação entre as pedagogias da essência (como ensinar) e as pedagogias da existência (como aprender)33, para a teoria curricular histórico-crítica o problema fundamental é a relação entre a produção, a socialização e a interiorização do saber elaborado, como totalidade concreta, ou simplesmente, a produção e a socialização do saber.

Assim, no âmbito do debate sobre uma teoria curricular históricocrítica, a análise do problema da periodização curricular deve tomar o processo de produção do trabalho educativo como objeto, seu instrumental, os agentes e as finalidades, no tempo do trabalho educativo, que é o tempo da catarse - forma superior da infraestrutura em superestrutura no pensamento dos seres humanos (GRAMSCl, 1978). Portanto, não se trata de qualquer trabalho educativo, pois não é qualquer trabalho educativo que produz a catarse, é o trabalho educativo que se preocupa em produzir em cada indivíduo singular o que a humanidade produziu histórica e coletivamente pelo conjunto dos seres humanos.

\subsection{Apontamentos sobre a periodização em geral}

Segundo o dicionário etimológico Hovaiss (2008), a periodização é o ato ou efeito de periodizar, periodizar+ção. Periodizar é separar ou dividir em períodos; expor em períodos; período+izar.

\footnotetext{
2 Ver Marx (2007; 2013); Lombardi (2010); Triviños (1987).

3 Ver Suchodolski (2002); Debesse (2002); Saviani (2003, 2008, 2013, 2017); Schimied-Kowarzi (1983).
} 
Me chamou a atenção a explicação da física, como segue em destaque: "intervalo de tempo ou de espaço entre estados idênticos de um sistema físico cujas propriedades variam periodicamente [No caso em que a variação periódica depende do tempo, o período corresponde ao tempo utilizado para completar um ciclo]".

Etimologicamente do grego períodos, ou caminho ao redor, circuito, giro, revolução dos astros, época periódica, período de tempo, pelo latim periodus, i 'id.'; 1601 é a data para a acepção de Medicina 'espaços de tempo', e 1667 é a data para a acepção 'tempo que transcorre'.

Na natureza, o "tempo utilizado para completar um ciclo" segue as leis naturais, as ocorrências são naturais; mas é fato que hoje estas leis têm sido influenciadas pela ação direta dos seres humanos na natureza, o que tem contribuído para alterar o tempo do ciclo natural e caracterizar um fato histórico de máxima importância, quero dizer, já há atividade humana interferindo significativamente na processualidade natural.

Entretanto, na periodização na sociedade, as determinações são histórico-sociais, estão situadas num espaço, datadas num tempo e em movimento.

Com isso estou afirmando que a periodização está na natureza e na sociedade, mas em circunstâncias distintas: na natureza, na medida em que a ordem lógica do curso dos acontecimentos é o princípio da possibilidade do estabelecimento de generalizações previsíveis, e por conseguinte a aquisição pela ideia dos cortes na continuidade dos acontecimentos naturais, caracterizando o caráter da periodização; e na sociedade, na construção do objeto e o tratamento do tempo, a partir do engajamento do ser humano no mundo dos fenômenos, na história, na ação de realizar o que idealiza.

Portanto, como afirmou Dermeval Saviani em sua História das ideias pedagógicas no Brasil, a periodização não é um dado empírico, isto é, não está inscrita no próprio movimento objetivo dos fenômenos. A periodização como uma forma histórico-social, "[...] é, antes, uma questão teórica que se 
põe para o historiador ao enfrentar a tarefa de organizar os dados visando a explicar o fenômeno que se propôs a investigar [...]".

Assim, o exame da questão, segundo Cardoso (1976 apud SAVIANI, 2007; CARDOSO, 1977), em parte implica "a construção do objeto histórico e o tratamento do tempo na explicação própria da ciência da história".

Construir o objeto histórico significa apreender e explicar as formas do ser em sua processualidade, e o tratamento do tempo significa que, de posse da ciência do ser, dever-se-á tratar o tempo do ser (particular) na explicação própria da ciência da história (universal), ou seja, apreender e explicar as formas do ser no tratamento do tempo estrutural e conjuntural, sem perder de vista a particularidade do objeto.

Com efeito, afirmou Saviani (2007, p. 12): "a explicação científica do objeto implica atingir um certo nível de generalidade, e para Cardoso (1976 apud SAVIANI, 2007, p. 12), a generalidade buscada 'se determina por um corte no tempo. Cortes diferentes, em momentos diferentes, constituem totalidades diferentes'". Daí que, assevera Saviani (Ibidem): "o problema do investigador consiste em definir onde fazer os cortes: 'Como dar conta das descontinuidades na continuidade dos acontecimentos? Como definir as descontinuidades através da periodização?'" (CARDOSO apud SAVIANI, 2007, p. 12).

A relação entre o ser (objeto) e o tempo (história) na particularidade da realidade, em condições sociais objetivas, constitui a estrutura geral da periodização. A construção do objeto pressupõe a apreensão de generalizações que marcam totalidades diferentes - que são as descontinuidades na continuidade na explicação própria da ciência da história. Segundo os autores (SAVIANI, 2007; CARDOSO, 1977), o princípio da periodização que the permitirá dar conta das descontinuidades dos eventos constitutivos do fenômeno investigado terá como base o sistema de categorias que o pesquisador irá mobilizar para explicar o seu objeto.

O problema da generalização e do critério da periodização são altamente relevantes. Vou analisar tais aspectos a partir de concepções sobre a periodização na história, na psicologia e na pedagogia, para 
problematizar uma noção de periodização em geral, para fins de análise da periodização curricular no trabalho educativo na educação escolar.

Segundo Saviani (2007, p. 12-14), na análise da produção sistematizada sobre a história da educação brasileira, é possivel encontrar o critério político, o "critério da determinação econômica", ambos critérios externos. Preliminarmente, Saviani afirma que em sua investigação sobre a história das ideias pedagógicas no Brasil, partiu das principais concepções de educação, e, guiando-se pelo próprio movimento das ideias pedagógicas, construiu uma periodização.

Em sua proposta de periodização, destaca vários eventos a partir dos quais foram definidos os seus marcos. Entretanto, na mesma obra, Saviani (2007, p. 17-18) afirma que, ao concluir o trabalho de pesquisa na primeira fase, manifestou-se a necessidade de examinar-se mais detidamente $\mathrm{O}$ problema da periodização, e levantou as seguintes indagações:

[...] os períodos mais recentes, pelo dinamismo da sociedade contemporânea, revelam especificidades objetivas que os distingue entre si, justificando-se, em consequência, o seu tratamento diferenciado? Indagava, ainda, se a história das ideias pedagógicas no Brasil poderia ser interpretada como uma sucessão de momentos sempre mais breves como resultado do adensamento do fenômeno educativo ou, ao contrário, o que estaria em causa seria o viés do pesquisador que, diante dos períodos mais distantes no tempo, cujo conhecimento já está mais sedimentado, os identifica pelas diferenças de estrutura, ao passo que em relação aos períodos mais recentes, cujas fontes não estão ainda sedimentadas, ele é levado a dar excessiva importância a diferenças de conjuntura tomando-as como indicadoras de períodos estruturalmente diferenciados (SAVIANI, 1999). Ficou então claro que, nessa última hipótese, eu estaria incorrendo no risco apontado por Gramsci (1975), para quem "o erro no qual se cai frequentemente nas análises histórico-políticas consiste em não saber encontrar a justa relação entre o que é orgânico e o que é ocasional" (SAVIANI, 2007, p. 18).

Em artigo intitulado Periodização na história da educação brasileira: aspecto polêmico e sempre provisório, Lombardi (2008) analisa que o problema central da periodização são os critérios que devem presidi-la, que podem ser internos ou externos ao objeto de investigação, mas que recoloque os determinantes econômicos, sociais, políticos e ideológicos da educação brasileira, e destaca: "[...] não se tem uma adequada 
compreensão do particular - qualquer aspecto da educação brasileira sem pressupor [...] a inseparável e indissociável articulação deste com a totalidade histórico-social [...]", pois, "É a periodização que expressa o entendimento de como ocorrem as mudanças estruturais, globais e profundas - as transformações históricas - e como se dá a transição de um período para o outro" (LOMBARDI, 2008, p. 200). Sobre o assunto, cita a posição do historiador Fernando Novais, como segue:

Transição, já se disse com alguma propriedade, é tudo em história, a ponto de a própria história poder definir-se como o estudo da transição (J. Ortega y Gasset). Se, de facto, se quer indicar a inexistência de limites radicais, o inexorável entrelaçar-se dos acontecimentos no curso da história, a permanente coexistência de formas transatas com antecipações ainda não concretamente definidas, a afirmação ganha sentido e exprime um dos traços essenciais da realidade histórica. E, no entanto, para certas épocas mais do que para outras, a própria sensibilidade e a tradição do pensamento historiográfico vêm revelando não ser desapropriado falar em transição e crise. É que, não obstante aquela inextricável interpenetração acima referida, o desenrolar da história é periodizado por estruturas globais e profundas, geradas na inevitável relacionação dos homens entre si na prática de sua vida histórica, e que passam a configurar o quadro de possibilidades em que se desenvolve a própria história (...) (NOVAIS,1995, apud LOMBARDI, 2008, p. 201, grifos nossos).

Por fim, Lombardi fundamenta sua posição na centralidade das categorias totalidade e contradição para uma necessária visão concreta da história da educação brasileira, em suas relações com a estrutura e conjuntura, como explicita:

O estudo da educação brasileira, portanto, atentando-se para as contradições internas da formação social brasileira e para a mediação de outros fatores que se articulam à organização escolar, à estrutura educacional e às práticas educativas formais e nãoformais, não pode ser teoricamente realizado sem pressupor, por sua vez, que a sociedade brasileira, desde sua origem, tem uma vinculação profunda com o sistema global - econômico, social e político - no qual se inseriu e se insere, sem estabelecer as necessárias articulações do Brasil com as transformações do sistema capitalista de produção (LOMBARDI, 2008, p. 206).

Em outra abordagem sobre $\mathrm{p}$ problema da periodização, na investigação psicológica do problema da idade, também com fundamento na ciência da história, Vygotsky (1996), no Tomo IV de suas Obras escolhidas, 
após realizar a crítica sistemática às concepções idealistas da periodização da idade, observa:

Sobre que princípios deve estruturar-se a verdadeira periodização? Já sabemos onde buscar seu verdadeiro fundamento: deve-se buscar nas mudanças internas do próprio desenvolvimento; tão só as viragens e giros de seu curso podem nos proporcionar uma base sólida para determinar os principais períodos de formação da personalidade da criança que chamamos de idade. Podemos reduzir todas as teorias do desenvolvimento infantil a duas concepções fundamentais. Para uma, o desenvolvimento não é mais que a realização, as mudanças e as combinações das capacidades inatas. Não surge nada de novo com exceção ao crescimento, desdobramento e reagrupamento dos elementos dados desde 0 princípio. Para a outra concepção, o desenvolvimento é um processo contínuo de automovimento, que se distingue, em primeiro lugar, pela permanente aparição e formação do novo, não existente em estágios anteriores. Esse ponto de vista sabe captar no desenvolvimento algo essencial para a compreensão dialética do processo.

Sobre o último ponto de vista, não há nem pode haver nenhum outro critério para distinguir os períodos concretos do desenvolvimento infantil ou das idades que o das formações novas, graças as quais se pode determinar o essencial em cada idade. Entendemos por formações novas o novo tipo de estrutura da personalidade e de sua atividade, as mudanças psíquicas e sociais que se produzem pela primeira vez em cada idade e determinam, em seu aspecto mais importante e fundamental, a consciência da criança, sua relação com o meio, sua vida interna e externa, todo o curso de seu desenvolvimento no período dado (VYGOTSKY, 1996, p. 254- 255).

E O autor conclui: "Isso, entretanto, não é suficiente para uma periodização científica do desenvolvimento infantil. É preciso, ademais, levar em conta sua dinâmica e a dinâmica dos passos de uma idade a outra [...]" (VYGOTSKY, 1996, p. 254- 255).

Sobre a noção de periodização curricular na educação escolar a partir de estudos do campo da educação que se colocam numa perspectiva histórico-crítica, destaco a noção de ciclos ${ }^{4}$ de escolarização sinalizada na obra Coletivo de Autores (1992) e na obra Fundamentos da didática histórico-crítica (MARSíGLIA; MARTINS; LAVOURA, 2019). Em se tratando da primeira fonte, pergunto: por que esta obra? Por que ela tem exercido influência em outras produções do campo, dissertações e teses,

\footnotetext{
4 É importante destacar o que Saviani (2008, p. 55) chamou de "novos mecanismos de recomposição de hegemonia burguesa".
}

Revista Exitus, Santarém/PA, Vol. 12, p. 01 - 25, e022012, 2022. 
inclusive na mais recente publicação sobre Fundamentos da didática histórico-crítica de autoria destes autores - nesta, com o devido cuidado no trato das questões postas ali, rejeitando, ajustando e incorporando o conteúdo daquela.

Segundo o Coletivo de autores (2009) o ciclos de escolarização é uma proposição para orientar a seleção, organização e sistematização do conhecimento no currículo. É uma forma sintética do que foi definido pelo Coletivo como "dinâmica curricular". No entanto, não há nem estudos sobre como se aprende, nem sobre como se desenvolve referenciados na obra. Apesar de o Coletivo afirmar a diretividade do processo pedagógico, subjuga $\bigcirc$ ato de ensinar às experiências dos alunos; entretanto, contraditoriamente, aborda a necessidade do conteúdo, da universalidade do conhecimento, o que torna conflituosa a relação entre a teoria do conhecimento proposta (ontologia e gnosiologia), o formalismo presente na análise das relações ensino-aprendizagem e o escolanovismo na orientação da seleção, organização e sistematização do conhecimento, quer dizer, estou afirmando que o Coletivo de Autores sofreu forte influência dos movimentos ${ }^{5}$ escolanovistas, mas também do debate crítico da proposição histórico-crítica no período, configurando um ecletismo na proposição, além de caracterizar-se como uma proposição não sistematizada ${ }^{6}$ nesse momento, mas em processo de sistematização, diferente do que afirmaram pesquisadores do campo (CASTELANE FILHO, 2013). Isso fica evidente quando o Coletivo afirma: "Dessa forma, os ciclos não se organizam por etapas. Os alunos podem lidar com diferentes Ciclos ao mesmo tempo, dependendo do(s) dado(s) que esteja $(\mathrm{m})$ sendo tratado(s) [...]" (COLETIVO DE AUTORES, 2009, p. 36, grifo nosso).

Vejam que os "ciclos de escolarização" aparece como uma espécie de "modelo da prática social" na educação escolar, uma espécie de estrutura máxima de generalização que deve orientar a atividade de ensino na educação física. O problema é que, sem analisar como a criança

\footnotetext{
5 Sobre a noção de "movimentos" ver Lombardi (2010).

${ }^{6}$ A não sistematização tem a ver com um problema de método.
} 
aprende e se desenvolve, com base numa concepção de realidade, de saber objetivo, portanto, numa concepção de ser humano, sociedade e conhecimento concretas, bem como sem tomar a centralidade da construção do objeto e seu tratamento no tempo no processo de trabalho educativo, na particularidade da transmissão-assimilação do conhecimento da educação física na educação escolar, seus critérios, em perspectiva histórica, como objeto de análise, ficou impossível tal proposição atender à concepção da prática social como critério de verdade, defendida pela lógica e teoria do conhecimento materialista histórico-dialética.

Segundo o Coletivo de Autores (2009, p. 65), os ciclos de escolarização são "[...] uma das formas possíveis de distribuição do conteúdo nos diversos ciclos do processo de ensino-aprendizagem [...]". Assim, os ciclos expressam formas de ser da relação ensino-aprendizagem, como períodos para organização do conhecimento nas séries. No entanto, em minha análise (FERREIRA, 2015; 2021), identifiquei que as explicações sobre os graus de desenvolvimento do pensamento propostos pelos ciclos conflitam com 1) as etapas da periodização da aprendizagem-desenvolvimento segundo as teses da psicologia histórico-cultural, bem como, 2) com a lógica do ensino proposta pela pedagogia histórico-crítica, não correspondendo ao que foi elaborado como seu "Método Pedagógico", e ainda 3) com o que defende Martins (2013) em sua tese sobre a unidade entre a psicologia históricocultural e a pedagogia histórico-crítica, ambas com base no método da economia política (MARX, 2008). Assim, tais proposições teóricometodológicas, reconhecidas como as expressões mais avançadas no campo da teoria pedagógica histórico-crítica fundadas no marxismo no Brasil, não corroboram tal concepção de organização do conhecimento e de ensino-aprendizagem proposta pelos ciclos de escolarização na concepção crítico-superadora. O que estou afirmando é que houve um problema em termos de análise, que tem relação com a concepção de realidade, com a ausência de unidade metodológica. Mas que precisa ser enfrentado e superado, e vem sendo. 
Numa análise da relação aprendizagem-desenvolvimento, com base na psicologia histórico-cultural, Leontiev (2004) sintetiza o que chamou de atividades dominantes: são aquelas atividades que devem orientar a aprendizagem-desenvolvimento dos indivíduos, seguindo uma dada periodização do desenvolvimento, que constitui uma contribuição para o desenvolvimento de estudos sobre o processo ensino-aprendizagem das crianças. De acordo com o autor, tais atividades são aquelas cujo desenvolvimento condiciona as principais mudanças nos processos psíquicos da criança e as particularidades psicológicas da sua personalidade num dado estágio do seu desenvolvimento, e que, portanto, possibilitam aos indivíduos a apropriação da experiência sócio-histórica acumulada nos objetos sociais. Mas isto não significa que a lógica do ensino esteja dada nas atividades dominantes. Esta é uma concepção errônea da relação ensinoaprendizagem. As atividades dominantes são graus do desenvolvimento do conhecimento e da prática social, portanto, configuram-se como expressões universais das relações entre os indivíduos consigo mesmo, com as formas objetivadas da realidade e com os outros seres humanos, na esteira da atividade, como unidade do diverso. As atividades dominantes expressam as contradições no processo de desenvolvimento humano, momentos predominantes que impulsionam transformações. Este conceito é extremamente produtivo para articular o problema da periodização curricular no processo de trabalho educativo na educação escolar. O desafio é produzir densidade necessária a este conceito. Uma via de realizar tal processo é explicitando a sua relação com base na atividade produtiva em geral - o trabalho. Aqui o conceito cresce e nos possibilita realizar análises do currículo (transmissão-assimilação do saber) a fim de contribuir para a elaboração do conceito como categorias da prática educativa, contribuindo, assim, para a construção da teoria da ciência pedagógica.

Depois de situar o problema e uma perspectiva de análise, agora vou trazer algumas reflexões que tenho realizado a fim de contribuir com o debate sobre uma perspectiva teórico-metodológica da periodização curricular no processo de trabalho educativo na educação escolar. 
Se a estrutura geral da periodização pressupõe a construção do objeto e o trato do tempo, como pensar a construção do objeto e o trato do tempo da periodização curricular no processo de trabalho educativo na educação escolar?

\subsection{A periodização curricular no processo de trabalho educativo na educação escolar}

$\mathrm{Se}$ a relação entre o ser (objeto) e o tempo (história) na particularidade da realidade, em condições sociais objetivas, constitui a natureza da periodização, com destaque para as descontinuidades na continuidade, na estrutura e conjuntura; a periodização curricular é a forma generalizada do processo de trabalho educativo (transmissão-assimilação do saber elaborado) no tempo, em condições sociais objetivas (estrutura e conjuntura).

A construção do objeto e o tratamento do tempo no processo de trabalho educativo pressupõe os instrumentos, as condições, os agentes, e a finalidade do trabalho educativo, no tempo, o tempo necessário à realização da catarse.

$\mathrm{Na}$ particularidade do trabalho educativo, a relação social que constitui a periodização curricular se realiza pela via dos objetos de cada área do conhecimento no processo de transmissão-assimilação do saber elaborado (conhecimento-desenvolvimento) na educação escolar.

Os instrumentos são os meios (objeto de cada área de conhecimento) e as condições para a realização do produto não material, que vão formando, pela via da transmissão-assimilação das significações objetivas, noções, juízos, conceitos, que vão produzindo neoformações psicológicas, como uma segunda natureza, a cultura.

O processo se realiza pela incorporação das propriedades e relações que constituem a significação objetiva na relação entre estrutura e conjuntura, pela via da contradição que se instala no processo de ensinoaprendizagem-desenvolvimento articulado ao objeto de cada área de conhecimento. 
Os agentes são professor e aluno, numa relação direta e mediada: professor-conhecimento e aluno-conhecimento, relações carregadas de propriedades afetivo-cognitivas.

A finalidade é a transmissão-assimilação do saber elaborado, que realiza o processo de trabalho educativo, como uma segunda natureza, a função social da educação escolar - realizar em cada indivíduo o gênero humano.

O produto não material é a forma generalizada (imagem) produzida pela via do instrumental disponibilizado no processo de trabalho educativo.

O produto não material pressupõe a incorporação das propriedades e relações dos objetos materiais e ideais em uma forma objetivada não material, na consciência dos agentes, e que pode se realizar também como uma forma física.

Outro fato é o que o resultado de uma cadeia de sínteses que produz neoformações psicológicas pode aparecer como condição para a realização de um novo produto material, de uma nova cadeia de sínteses.

O tempo é a duração da dinâmica histórico-social da estrutura no processo de trabalho educativo em sua especificidade (disciplinas) - a realização da catarse.

Mas, qual é o tempo da catarse no processo de trabalho educativo? Se o tempo se refere à duração da dinâmica histórico-social relativa das coisas, dos eventos, portanto, das relações entre o instrumental, os agentes, as finalidades e o produto não material da atividade educativa, e constituem a processualidade do trabalho educativo que leva a catarse; que articula, pela análise, processo de conhecimento e processo de interiorização no trabalho educativo, em meios e condições sociais objetivas; que marca a continuidade e descontinuidade entre um período e outro; então o tempo da catarse é o tempo necessário para a produção de um produto não material, que pode ser físico ou mental, porém, que realize a finalidade do processo de trabalho educativo.

Mas como conhecer e explicar, para fins de instrumentalizar a periodização curricular, o tempo necessário para a produção de um 
produto não material no trabalho educativo? E qual o critério para periodizar o currículo?

A forma de conhecer e determinar esse tempo só poderá ser apreendida pela análise das propriedades e relações que constituem a forma objetivada do processo de trabalho educativo, carregada de trabalho humano não material incorporado, numa relação indireta e mediada.

O critério é a determinação que impulsiona a formação do novo, a nova formação, a nova imagem subjetiva da realidade objetiva, produzida direta e intencionalmente em cada indivíduo singular, no processo de trabalho educativo, na dinâmica de um período a outro, em condições sociais objetivas (estrutura e conjuntura).

A objetivação ou produto do trabalho não material deve explicitar o conteúdo e a forma da nova formação material/ideal.

Entretanto, apesar de ser altamente relevante e condicionante, a produção de uma nova formação mental não é suficiente.

Por isso que o conceito de catarse em Gramsci é importante para pensar o critério da periodização curricular, quer dizer, não basta identificar a atividade dominante que impulsiona a transição. Vamos analisar.

Segundo Gramsci (1978, p. 53), "Pode-se empregar a expressão "catarsis" para indicar a passagem do momento puramente econômico lou egoísta-passional) ao momento ético-político, isto é, a elaboração superior da estrutura em superestrutura na consciência dos seres humanos".

Ainda segundo o autor, "Isso significa, também, a passagem do "objetivo ao subjetivo" e da "necessidade à liberdade" [...]. Tal passagem só pode se realizar nas condições do modo de produção capitalista pela via da contradição, pois, ao entender que é esta que move o real, na cadeia de ações e operações, a contradição aparece como a determinação do modo de ser dos momentos predominantes, resultado de uma processualidade objetivo-subjetiva, o verdadeiro ponto de partida da filosofia da práxis, como analisa Gramsci (1978, p. 53): 
A estrutura da força exterior que subjuga o homem, assimilando-o e o tornando passivo, transforma-se em meio de liberdade, em instrumento para criar uma nova forma ético-política, em fonte de novas iniciativas. A fixação do momento "catártico" torna-se assim, creio, o ponto de partida de toda a filosofia da práxis; o processo catártico coincide com a cadeia de sínteses que resultam do desenvolvimento dialético (GRAMSCl, 1978, p. 53).

Portanto, a catarse é uma produção material/ideal do movimento contraditório da realidade historicamente determinada, uma elaboração superior da infraestrutura em superestrutura na consciência dos homens critério da atividade dominante na periodização curricular.

A contradição é a condição que realiza a finalidade da atividade, em uma situação social objetiva sem a qual a atividade fica comprometida, pois a prática é o critério de verdade da catarse.

Assim sendo, a catarse é a síntese entre o particular e o universal, e os meios e condições no processo de trabalho educativo são fundamentais para fazer mover o real, concreto, no trabalho educativo - o critério da periodização curricular. É critério porque articula processo (método) e produto (teoria), indivíduo e sociedade.

Na totalidade da periodização curricular, um conjunto de mediações, instrumentos, são postos em movimento no processo de transmissãoassimilação da cultura elaborada no trabalho educativo, a fim de realizar em cada indivíduo singular o gênero humano.

Para tanto, toma como critério o tempo da catarse, somente apreendido e explicado por via indireta e mediada, ou seja, pela condição que produz o resultado/ produto/finalidade do trabalho educativo, e o tempo necessário para a produção de um produto não material no trabalho educativo, como vimos, é o tempo da catarse. Vamos avançar um pouco mais.

Para Saviani (2003), faz-se necessário que os agentes tenham atenção para que a fixação de certos mecanismos aconteça, a fim de incorporá-los, torná-los parte de nosso corpo, a fim de alcançar a libertação de tais mecanismos. 
A libertação ocorre quando os mecanismos são apropriados, dominados, internalizados, passando a operar no interior de nossa própria estrutura orgânica, quando os aspectos mecânicos são negados por incorporação, superados porque negados enquanto elementos externos e afirmados como elementos internos, como hábito.

Assim, só se aprende de fato, quando se adquire um habitus, isto é, uma disposição permanente, ou, dito de outra forma, quando o objeto de aprendizagem se converte numa espécie de segunda natureza.

$E$ isso exige tempo e espaço por vezes ingentes, para que a habilidade se realize, a fim de superar por incorporação o mecanismo (SAVIANI, 2003).

Ainda segundo o autor, adquirir um hábito significa criar uma situação irreversível. Assim, entende-se que o tempo, os instrumentos e os agentes, orientados a finalidades são centrais para que tal processo se realize num produto não material, para que o acontecimento se realize, para que 0 automatismo se realize como expressão da liberdade.

Segundo Dermeval Saviani (informação verbal)7, o currículo não deve ser uma criação da cabeça dos homens, mas a possibilidade para iniciar os estudantes nas leis da natureza e da sociedade, afirmando que as leis evidenciadas pela ciência, expressam algo que está em vigor na história e que as pessoas não conhecem.

Nesse sentido, afirmou o autor que o aprendiz só é livre quando aprende o conteúdo, e se liberta. O educando não pode ser livre enquanto não se libertar do objeto da aprendizagem.

Assim, o currículo deve rejeitar ou incorporar o que está posto para fazer avançar o projeto de sociedade. Sobre o currículo do Ensino Médio, destaca Saviani $(2007 ; 2019)$ que no ensino médio já não basta dominar os elementos básicos e gerais do conhecimento que resultam e ao mesmo tempo contribuem para o processo de trabalho na sociedade. Trata-se, agora, de explicitar como o conhecimento (objeto específico do processo

\footnotetext{
7 Arguição realizada em Banca de defesa de tese de Julia Malanchen (2014), de título "A PHC e o currículo: para além do multiculturalismo das políticas curriculares nacionais", na qual foi membro externo.
} 
de ensino), isto é, como a ciência, potência espiritual, se converte em potência material no processo de produção.

Isto significa que "Tal explicitação deve envolver o domínio não apenas teórico, mas também prático sobre o modo como o saber se articula com o processo produtivo" (Ibidem) num determinado estágio de desenvolvimento das forças produtivas e relações de produção.

Para que o trabalho educativo produza em cada indivíduo singular o gênero humano é necessário um instrumental orientado à finalidade do processo de trabalho educativo, propriedades e relações que estão em estado latente nos conteúdos, no tempo conjuntural e estrutural, que explicitem as determinações econômicas, políticas, históricas, sociais entre o particular e o universal.

Aqui o conceito de hegemonia é central, bem como o conceito de alienação, para uma apropriação crítica do conteúdo da realidade.

Mas como se dá o processo de interiorização no trabalho educativo na educação escolar? Como afirmou Vigotsky em sua "lei genética geral do desenvolvimento cultural do psiquismo [...] toda função no desenvolvimento cultural da criança aparece em cena em dois planos; em princípio entre os seres humanos como categoria interpsíquica e logo no interior da criança como categoria intrapsíquica" (VIGOTSKI, 2000, p. 150). Este processo se realiza pela via do instrumento psicológico, que se converte no centro do foco estrutural, na medida em que se determina funcionalmente todos os processos que dão lugar ao ato instrumental (VIGOTSKI, 2004, p. 96). Segundo o autor russo, o instrumento provoca 1) a atividade de toda uma série de funções novas, relacionadas com a utilização do mencionado instrumento e de seu manejo; 2) suprime e torna desnecessária toda uma série de processos naturais, cujo trabalho passa a ser efetuado pelo instrumento; 3) modifica também o curso e as diferentes características (intensidade, duração, sequência etc.) de todos os processos psíquicos que fazem parte do ato instrumental, substituindo certas funções por outras, processo genético-histórico que constitui a base material que explica a lei genética geral do desenvolvimento do psiquismo (Ibidem). 
No processo de produção do saber no ensino, a apropriação e objetivação dos instrumentos/meios artificiais que movem o conteúdo objetivo real ganha relevância na medida em que a sua interiorização cria as condições para a aprendizagem e desenvolvimento no psiquismo dos estudantes, condição para o domínio dos bens de produção acumulados na atividade.

No processo de socialização do saber, o domínio da lógica de ação do conteúdo, pela via da mediação do "ato instrumental", significa a disponibilização dos meios para a realização do consumo produtivo do processo que move o conteúdo do real, em condições históricas particulares, com todo um conjunto de determinações concretas, no caso da ciência, um movimento que se desloca do movimento exterior ao movimento interior do fenômeno. Aqui a história, o trabalho e a linguagem são centrais.

Por essa razão, Vigotski (2000) afirma o signo como o nexo essencial ou nova formação que impulsiona o desenvolvimento das funções psicológicas "elementares" em superiores.

Este desenvolvimento, ao ser conduzido pelas ações verbais, o signo vai se transformando em conceitos na medida em que a atividade humana se complexifica, constituindo o que Vigotski definiu como sistemas psicológicos, pois o conceito é conhecido em suas relações e vinculações, "é um sistema de apreciações, reduzidas a uma determinada forma regular, quer dizer, uma forma generalizada do real (VIGOTSKY, 2004, p. 122).

Todo conceito é um sistema de conceitos, mas todo conceito é produzido pela formação de noções, juízos, até os conceitos embrionários, conceitos mais elaborados, categorias etc., que constituem a lógica do ser na história.

O conceito é produzido como unidade inter e intrafuncional na esteira da atividade, quer dizer, é na relação entre as funções que aparecem os novos agrupamentos desconhecidos do nível anterior.

O que muda para que surjam estas novas formações são as relações sociais acessadas pelos indivíduos, o que possibilita uma espécie de 
reorganização das funções, pois, ao surgir um novo sistema psicológico, este se converte no centro do foco estrutural, na medida em que determina funcionalmente todos os processos que dão lugar à mediação do "ato instrumental".

Isto significa que a realização da atividade em suas formas complexas possibilita a produção no psiquismo do sujeito de operações, ações, até as formas mais complexas da atividade humana, como um processo sem fim (VIGOTSKY, 2004).

O acesso aos conteúdos culturais com maior acúmulo de atividade humana condensada, cria estofo para o processo de interiorização, em condições sociais objetivas, desencadeando um conjunto de neoformações psicológicas, centrais para a formação da consciência, da personalidade e da concepção de mundo (VIGOTSKI, 2000, 2004; LEONTIEV, 2004; LURIA, 1979a, 1979b).

Portanto, o não acesso às formas mais elaboradas das atividades humanas limita as capacidades dos sujeitos, o desenvolvimento do seu pensamento conceitual, pois "[...] o pensamento não pode ser outra coisa senão uma imagem subjetiva do mundo objetivo [...]. Ao mesmo tempo, o pensamento é objetivo porquanto se desenvolve pela via da criação de uma imagem ideal que reflete o objeto com plenitude e precisão" [...]. Nesse mesmo sentido, por conteúdo, o pensamento procura ser adequado à coisa objetiva, descobrir as propriedades do objeto tais como elas existem independentes do pensamento (KOPNIN, 1978, p. 127).

Feitas essas análises, observo que não poderei me deter mais aqui à processualidade de uma disciplina curricular, pois não tenho espaço neste momento, no entanto, destacarei nas considerações finais algumas sínteses, ainda que provisórias.

\section{CONSIDERAÇÕES FINAIS}

A construção do objeto curricular pressupõe a relação entre a produção e a socialização do saber elaborado no processo de trabalho 
educativo na educação escolar. Esta relação implica a análise da unidade conhecimento-desenvolvimento humano.

Sobre o tratamento do tempo, analisei que o tempo é a processualidade do objeto, quero dizer que o tempo pressupõe toda a dinâmica do acontecimento que constitui a processualidade da relação entre conhecimento e desenvolvimento (O-S). O tempo é uma abstração, o tempo é uma forma generalizada da processualidade dessa dinâmica que se realiza. O tempo é o conjunto de nexos que vão, no processo do trabalho educativo, realizando-se como acontecimento. O acontecimento é composto por um conjunto de elementos externos e internos - os agentes, as condições, os meios, as finalidades, que significam motivos e sentido pessoal -. Todo esse movimento entre esses componentes constitui o acontecimento do processo de trabalho educativo que pode expressar formas gerais da periodização.

Quando se adentra à dinâmica interna da produção do objeto curricular na análise da periodização, há necessidade de apreender as determinações que constituem o objeto das disciplinas curriculares na particularidade do trabalho educativo. Assim, a explicitação sobre a construção do objeto da disciplina curricular educação física, por exemplo, constitui-se numa dinâmica própria em sua particularidade-universalidade, produzida num conjunto de contradições que desencadeiam generalizações no processo de desenvolvimento do sujeito na particularidade das atividades nucleares desta disciplina. Entretanto, as generalizações na particularidade, apesar de universais em termos do objeto deste tipo de atividade, sempre serão limitadas com relação à periodização curricular no processo de trabalho educativo em geral, pois se trata da configuração da construção do objeto e do tratamento do tempo de apenas uma disciplina curricular. Não quero dizer que não é possível realizar generalizações sobre o processo de trabalho educativo em geral, por exemplo, a partir da disciplina curricular educação física ${ }^{8}$, mas, em relação

\footnotetext{
8 Ver Ferreira (2021).
} 
a periodização curricular, há peculiaridades, pois a relação objeto-sujeitotempo possui configurações diferenciadas. Um dos erros do Coletivo de autores (2009) quando organizou o ciclos de escolarização foi não compreender esta questão metodológica fulcral.

Já o trato do tempo se realiza em função da processualidade do ser no trabalho educativo, que pela via dos agentes, instrumental, condições, finalidade, que significam o motivo e sentido pessoal da atividade, que pela via das contradições produzidas, chega-se à catarse, em condições objetivas.

O tempo se movimenta no interior da dinâmica curricular que articula - desenvolvimento da corporalidade (a relação ativa, consciente e intencional entre o indivíduo e seu corpo, mediada, o objeto da disciplina curricular educação física)9, em condições sociais objetivas, com as determinações estruturais e conjunturais.

A unidade entre a construção do objeto e o trato do tempo como problema geral da periodização curricular, e a análise da relação social que constitui a periodização curricular a partir do critério de catarse, como via teórico-metodológica, vai expressar um conjunto de generalizações que pode configurar elementos de uma periodização curricular.

Para que esse processo se realize de conjunto faz-se necessário um esforço imenso de um coletivo de pesquisadores, num processo de trabalho organizado que articule o trabalho educativo em geral e a particularidade do trabalho educativo no interior das disciplinas curriculares na educação escolar.

Assim, a configuração de uma periodização curricular em geral pressupõe o todo como síntese de múltiplas determinações. Quero dizer que não pode haver periodização curricular em geral sem a construção do objeto e o tratamento do tempo, da dinâmica do ser, no processo de trabalho educativo nas disciplinas particulares, ou seja, se por um lado, o particular-universal dos objetos das disciplinas curriculares não expressa a

\footnotetext{
9 Ver Ferreira $(2015 ; 2021)$.
} 
universalidade da periodização curricular em geral, por outro, a universalidade da periodização curricular não poderá ser realizada sem a construção do objeto e o trato do tempo na particularidade das disciplinas curriculares no processo de trabalho educativo escolar.

A catarse é o critério porque é uma forma material/ideal da processualidade contraditória da realidade; mas a catarse não é fim, a catarse é meio para se realizar os objetivos da educação, e mais: para que a potência espiritual se converta em potência material (ato), como força produtiva que move o real.

E aí está um desafio imenso, pois envolve a dinâmica social, os condicionantes sociais, a estrutura e conjuntura de uma sociedade determinada, num tempo histórico determinado, pois a construção do objeto e o trato do tempo na periodização curricular precisa passar pelo crivo do movimento orgânico, e dialogar com o movimento conjuntural, portanto, não é possível haver fixidez na periodização curricular, mas é possível o estabelecimento de determinadas sínteses que levem em consideração a particularidade do fenômeno na relação com os condicionantes sociais.

Diante disso, pergunto: o que se realiza no interior da processualidade do ser em cada particularidade e o trato do tempo, que pode configurar formas da periodização curricular em geral? A resposta a esta questão pode contribuir para a sistematização de uma periodização que, ao levar em consideração a processualidade de cada objeto curricular, contribua para uma noção ampliada da periodização curricular articulada à teoria da ciência, à teoria da ciência pedagógica, à teoria psicológica e à teoria curricular. A apreensão da processualidade de cada objeto curricular é fundamental para fazer avançar uma periodização curricular pois pressupõe o diálogo entre as determinações que advém da particularidade, no interior do processo de trabalho educativo escolar em geral.

Assim, pensar em uma periodização curricular para a disciplina educação física na escola pode nos levar a erros, quero dizer que a periodização curricular precisa dialogar com a dinâmica do trabalho 
educativo em geral, bem como a análise de cada forma de ser particular que o constitui, no tempo escolar, que envolve todo um conjunto de determinações que faz a escola ser o que é.

Então teremos maior viabilidade para colocar em movimento uma proposta de periodização. Me parece que aqui o objeto ganha corpo e possibilidade para fazer avançar o estudo a partir de uma crítica ao tratamento dado ao objeto pelas teorias curriculares, para a posterior elaboração e sistematização da teoria crítica.

\section{REFERÊNCIAS}

CARDOSO, M. L. A periodização e a ciência da história: observações preliminares. Rio de Janeiro, PUC-Rio. Mimeografado. 1977.

CASTELANE FILHO, L. As concepções de educação física no Brasil. Horizontes - Revista de Educação, [S. I.] , v. 1, n. 2, p. 11-31, 2013. s/DOI. Disponível em: https://ojs.ufgd.edu.br/index.php/horizontes/article/view/3162/1712. Acesso em: 30 Ago. 2021.

COLETIVO DE AUTORES. Metodologia do ensino de educação física. São Paulo: Cortez, 2009.

DEBESSE, M. Prefácio. In: SUCHODOLSKI, B. A Pedagogia e as grandes correntes filosóficas: a pedagogia da essência e pedagogia da existência. Tradução de Rubens Eduardo Frias. São Paulo: Centauro, 2002.

FERREIRA, A. L. A. A Atividade de Ensino na Educação física: a relação dialética entre conteúdo e forma. 2015. 258f. Tese (Doutorado em Educação) - Universidade Federal da Bahia, Salvador/BA, 2015.

FERREIRA, A. L. A. A pedagogia como ciência da educação e o processo de trabalho educativo na educação escolar: a questão da periodização curricular. 2021. 204 f. Relatório de Pesquisa (Pós-doutorado em Filosofia e História da Educação) - Universidade Estadual de Campinas, Campinas-SP, 2021.

GRAMSCl, A. Concepção dialética da história. Rio de Janeiro: Civilização Brasileira. 3. ed. Rio de janeiro: Civilização brasileira, 1978.

HOUAISS. Grande dicionário Houaiss da língua portuguesa. Rio de Janeiro: Editora Objetiva, 2008. 
KOPNIN, P. V. A dialética como lógica e teoria do conhecimento. Tradução de Paulo Bezerra. Rio de Janeiro: Civilização Brasileira, 1978.

LOMBARDI, J. C. Periodização na história da educação brasileira: aspecto polêmico e sempre provisório. Revista HISTEDBR online, [S. I.] , n. 32, p. 200-209. 2008. s/DOI. Disponível em: https://www.fe.unicamp.br/pf-

fe/publicacao/5407/art14_32.pdf. Acesso em: 20 Jun. 2020.

LOMBARDI, J. C. Reflexões sobre educação e ensino na obra de Marx e Engels. 2010. 377f. Tese (livre docência) - Universidade Estadual de Campinas, Campinas/SP, 2010.

LURIA, A. R. Curso de psicologia geral. Vol I. Tradução de Paulo Bezerra. Rio de Janeiro: Civilização Brasileira, 1979a.

LURIA, A. R. Curso de psicologia geral. Vol IV. Tradução de Paulo Bezerra. Rio de Janeiro: Civilização Brasileira, 1979b.

MARX, K. A ideologia alemã: crítica da mais recente filosofia alemã em seus representantes Feverbach, Baver e Stirner, e do socialismo alemão em seus diferentes profetas. Tradução de Rubens Enderle, Nélio Shneider e Luciano Cavini Martorano. São Paulo: Boitempo, 2007.

MARX, K. O capital: crítica da economia política. Livro l: o processo de produção do capital. Tradução de Rubens Enderle. São Paulo: Boitempo, 2013.

MARX, K. Contribuição à Crítica da Economia Política. São Paulo: Expressão Popular, 2008.

MARTINS, L. M. O desenvolvimento do psiquismo e a educação escolar: contribuições à luz da psicologia histórico-cultural e da pedagogia históricocrítica. Campinas, SP: Autores Associados, 2013.

MARSíGLIA, A. C.; MARTINS, L. M.; LAVOURA, T. N. et al. Fundamentos da didática histórico-crítica. Campinas: Autores Associados, 2019.

SAVIANI, D. Educação: do senso comum à consciência filosófica. 14. ed. (revista). Campinas, SP: Autores Associados, 2002.

SAVIANI, N. Saber Escolar, Currículo e Didática: problemas da unidade conteúdo/forma no processo pedagógico. 4. ed. (revisada e ampliada). Campinas, SP: Autores Associados, 2003.

SAVIANI, D. História das Ideias Pedagógicas no Brasil. Autores Associados: Campinas, SP, 2007. 
SAVIANI, D. A Pedagogia no Brasil: história e teoria. Campinas, SP: Autores Associados, 2008a.

SAVIANI, D. Escola e democracia. Edição comemorativa. Campinas, SP: Autores Associados, 2008b.

SAVIANI, D. Escola e democracia: para além da "teoria da curvatura da vara". Clássicos. Germinal: Marxismo e Educação em Debate, [S. I.] , v. 5, n. 2, p. 227-239, 2013. DOl: https://doi.org/10.9771/gmed.v5i2.9713. Disponível em: https://periodicos.ufba.br/index.php/revistagerminal/article/view/9713. Acesso em: 1 Mar. 2021.

SAVIANI, D. "Da inspiração à formulação da Pedagogia Histórico-Crítica (PHC). Os três momentos da PHC que toda teoria verdadeiramente crítica deve conter". Interface - Comunicação, Saúde, Educação, [S. I.] , V. 21, n. 62, p. 711-24. 2017. DOI: 10.1590/1807-57622017.0001. Disponível em:

https://www.scielo.br/j/icse/a/tPJYjtq6473tpSkqTQkNZWm/?lang=pt\&format= pdf. Acesso em: 1 Mar. 2021.

SCHIMIED-KOWARZIK, W. Pedagogia Dialética. Tradução de Wolfgang Leo Maar. São Paulo: Brasiliense, 1983.

SUCHODOLSKI, B. A Pedagogia e as grandes correntes filosóficas: a pedagogia da essência e pedagogia da existência. Tradução de Rubens Eduardo Frias. São Paulo: Centauro, 2002.

TRIVIÑOS, A. N. S. Introdução à Pesquisa em Ciências Sociais: a Pesquisa Qualitativa em Educação. O Positivismo. A Fenomenologia. O Marxismo. São Paulo: Editora Atlas, 1987.

VIEIRA PINTO, A. Ciência e existência. Rio de Janeiro: Paz e Terra, 1985.

VIGOTSKI, L. S. Teoria e método em psicologia. São Paulo: Martins Fontes, 2004.

VYGOTSKY, L. S. Obras Escogidas. Vol IV. Tradução de Lydia Kuper. Madri: Visor, 1996.

VYGOTSKY, L. S. Obras Escogidas. Vol III. Traducción de Lydia Kuper. Madri: Visor, 2000

ZAPOROZHETS, A. V. El Papel de la actividad orientadora y la imagen em la formación y realización de los movimientos voluntários. In: ROJAS, L. Q.; SOLOVIEVA, Y. (Orgs). Las funciones psicológicas em el desarrollo del niño. México: Trillas, 2009a. 